Research Paper

\title{
Risk Factors Associated with Decreased Renal Function after Hand-Assisted Laparoscopic Donor Nephrectomy: A Multivariate Analysis of a Single Surgeon Experience
}

\author{
Jinwook Lim ${ }^{1 *}$, Yu-Gyeong Kong ${ }^{*}$, Young-Kug Kim ${ }^{1 凶}$, and Bumsik Hong ${ }^{2 \bowtie}$ \\ 1. Department of Anesthesiology and Pain Medicine, Asan Medical Center, University of Ulsan College of Medicine, Seoul, Republic of Korea; \\ 2. Department of Urology, Asan Medical Center, University of Ulsan College of Medicine, Seoul, Republic of Korea. \\ "Jinwook Lim and Yu-Gyeong Kong are co-first authors.
}

$\triangle$ Corresponding authors: Young-Kug Kim, MD, PhD, Professor, Department of Anesthesiology and Pain Medicine, Asan Medical Center, University of Ulsan College of Medicine, 88, Olympic-ro 43-gil, Songpa-gu, Seoul 05505, Republic of Korea. Tel.: 82-2-3010-5976; Fax: 82-2-3010-6790; E-mail: kyk@amc.seoul.kr; Bumsik Hong, MD, PhD, Professor, Department of Urology, Asan Medical Center, University of Ulsan College of Medicine, Seoul 05505, Republic of Korea. Tel: 82-2-3010-3980; Fax: 82-2-477-8928; Email: bshong@amc.seoul.kr.

(c) Ivyspring International Publisher. This is an open access article distributed under the terms of the Creative Commons Attribution (CC BY-NC) license (https:// creativecommons.org/licenses/by-nc/4.0/). See http://ivyspring.com/terms for full terms and conditions.

Received: 2016.09.15; Accepted: 2016.12.21; Published: 2017.02.08

\begin{abstract}
Background: Hand-assisted laparoscopic donor nephrectomy is a minimally invasive procedure for living kidney donation. The surgeon operative volume is associated with postoperative morbidity and mortality. We evaluated the risk factors associated with decreased renal function after hand-assisted laparoscopic donor nephrectomy performed by a single experienced surgeon.

Methods: We included living renal donors who underwent hand-assisted laparoscopic donor nephrectomy by a single experienced surgeon between 2006 and 2013. Decreased renal function was defined as an estimated glomerular filtration rate (eGFR) of $<60 \mathrm{~mL} / \mathrm{min} / 1.73 \mathrm{~m}^{2}$ on postoperative day 4 . The donors were categorized into groups with postoperative eGFR $<60$ $\mathrm{mL} / \mathrm{min} / 1.73 \mathrm{~m}^{2}$ or $\geq 60 \mathrm{~mL} / \mathrm{min} / 1.73 \mathrm{~m}^{2}$. Univariate and multivariate logistic regression analyses were performed to evaluate the risk factors associated with decreased renal function after hand-assisted laparoscopic donor nephrectomy. The hospital stay duration, intensive care unit admission rate, and eGFR at postoperative year 1 were evaluated.

Results: Of 643 patients, 166 (25.8\%) exhibited a postoperative eGFR of $<60 \mathrm{~mL} / \mathrm{min} / 1.73 \mathrm{~m}^{2}$. Multivariate logistic regression analysis demonstrated that the risk factors for decreased renal function were age [odds ratio ( $95 \%$ confidence interval), $1.062(1.035-1.089), P<0.001$ ], male sex [odds ratio ( $95 \%$ confidence interval), $3.436(2.123-5.561), P<0.001$ ], body mass index (BMI) [odds ratio ( $95 \%$ confidence interval), 1.093 (1.016-1.177), $P=0.018$ ], and preoperative eGFR [odds ratio ( $95 \%$ confidence interval), $0.902(0.881-0.924), P<0.001]$. There were no significant differences in postoperative hospital stay duration and intensive care unit admission rate between the two groups. In addition, 383 of 643 donors were analyzed at postoperative year 1. Sixty donors consisting of 14 (5.0\%) from the group of 279 donors in eGFR $\geq 60 \mathrm{~mL} / \mathrm{min} / 1.73 \mathrm{~m}^{2}$, and $46(44.2 \%)$ from the group of 104 donors in eGFR $<60 \mathrm{~mL} / \mathrm{min} / 1.73 \mathrm{~m}^{2}$ had eGFR $<60 \mathrm{~mL} / \mathrm{min} / 1.73 \mathrm{~m}^{2}$ at postoperative year $1(P<0.001)$.

Conclusions: Increased age, male sex, higher BMI, and decreased preoperative eGFR were risk factors for decreased renal function after hand-assisted laparoscopic donor nephrectomy by a single experienced surgeon. These results provide important evidence for the safe perioperative management of living renal donors.
\end{abstract}

Key words: decreased renal function, hand-assisted laparoscopic donor nephrectomy, single surgeon. 


\section{Introduction}

Kidney transplantation remains the standard treatment for end-stage renal disease, and the incidences of living donor nephrectomy continue to increase owing to the shortage of donor organs and increases in the number of patients with end-stage renal disease [1]. Living donor nephrectomy is a unique surgical procedure that requires organ donation from a healthy person to ensure a successful operation. Therefore, the safety of the donor is a priority. Living donor nephrectomy has medical outcomes that are similar to those in the general population [2]. However, extensive removal of normal renal tissue may lead to glomerulosclerosis in the remaining kidney that can progress to renal failure [3-5]. Therefore, advanced surgical techniques and meticulous perioperative management are required for the safety of living renal donors.

Among various surgical techniques that have been introduced, hand-assisted laparoscopic donor nephrectomy is the most recent; as compared with open nephrectomy and laparoscopic donor nephrectomy, its potential advantages include a shorter operative time, shorter learning curve, and decreased postoperative morbidity [6, 7]. For many surgical procedures, a high surgeon operative volume is associated with decreased postoperative morbidity and mortality, blood transfusions, postoperative infection, bleeding, and medical complications [8-11]. High surgeon operative volume is also related to improved outcomes including reduced operative time and hospital stay duration in radical prostatectomy [8, 9]. However, there is limited information about the risk factors that influence the outcomes of only one type of operative technique and a technique performed by a single surgeon in living renal donors.

Therefore, the present study aimed to evaluate the risk factors associated with decreased renal function after hand-assisted laparoscopic donor nephrectomy performed by a single experienced surgeon. Postoperative renal function was evaluated on the basis of estimated glomerular filtration rate (eGFR) calculated by using the Chronic Kidney Disease Epidemiology Collaboration (CKD-EPI) equation on postoperative day 4 [12].

\section{Methods}

This was a single-center, retrospective observational study of living renal donors who underwent hand-assisted laparoscopic donor nephrectomy by a single experienced surgeon (B.H.) at Asan Medical Center, Seoul, Republic of Korea, between 2006 and 2013. The study protocol was approved by the Institutional Review Board of Asan
Medical Center (approval number 2015-0022). Electronic medical records were reviewed to evaluate the risk factors associated with postoperative decreased renal function. Patients with incomplete medical records were excluded from the present study.

\section{Anesthetic technique}

Anesthesia was induced with thiopental, fentanyl, and vecuronium, and was maintained by using sevoflurane, desflurane, or isoflurane with a $50 \%$ oxygen/air mixture. Mechanical ventilation was performed with a constant tidal volume of 8-10 $\mathrm{mL} / \mathrm{kg}$ and a respiratory rate of $10-14$ cycles $/ \mathrm{min}$. End-tidal carbon dioxide tension was maintained between 30 and $35 \mathrm{mmHg}$ during surgery. Electrocardiography, heart rate, body temperature, and peripheral oxygen saturation were routinely monitored. Arterial blood pressure was also monitored by inserting a 20-gauge radial artery catheter.

Fluid management was performed according to our institutional protocol. A crystalloid solution (Hartmann's solution) was administered in all donors. However, synthetic colloids, including 6\% hydroxyethyl starch or gelatin, were not used. After surgical incision, mannitol $(0.5 \mathrm{~g} / \mathrm{kg})$ was routinely administered in all donors. Then, heparin (5000 U; before clamping the renal artery) and protamine (50 $\mathrm{mg}$; after donor nephrectomy) were intravenously administered.

\section{Surgical technique}

The donor was placed in the lateral position, and an incision was made in the midline above or below the umbilicus-for the left or right kidney, respectively.

For the left side, a hand port device (Applied GelPort; Applied Medical, Rancho Santa Margarita, CA), a 12-mm camera trocar, and two additional working laparoscopic ports were inserted. The gonadal, adrenal, and lumbar veins were controlled by using 3-0 black silk one-hand ties. An initial posterior and inferior dissection of the hilum was performed, and anterior and superior dissection was subsequently performed to completely free the hilum. After transection of the ureter, the renal artery was controlled by using a single Hem-o-lok clip (Weck Closure System, Research Triangle Park, NC) and two metal clips, and the renal vein was controlled by using an EndoGIA stapler (Endopath ETS articulating linear cutters; Ethicon, Irvine, CA).

For the right side, a 12-mm camera trocar, a 12-mm laparoscopic port, and an additional 5-mm port were inserted. To gain the maximum length of 
the right renal vein, the kidney was smoothly retracted laterally by the surgeon's left hand to extend the right renal vein, and an EndoGIA stapler was placed at the confluence of the inferior vena cava and right renal vein.

\section{Definition of decreased renal function}

To evaluate postoperative renal function, the eGFR levels were consistently obtained on postoperative day 4 , the earliest date on which the last follow-up examination of the eGFR is performed before living donors are discharged. In this study, the eGFR level measured immediately before discharge was considered a decisive factor in planning the post-discharge treatment. The postoperative eGFR levels measured immediately before discharge may be regarded as an important guide that may facilitate the creation of a meticulous post-discharge management plan. Preoperative eGFR was calculated by using the CKD-EPI equation: eGFR $\left(\mathrm{mL} / \mathrm{min} / 1.73 \mathrm{~m}^{2}\right)=141 \times$ minimum (serum creatinine/ $\mathrm{k}$ or 1$)^{\alpha} \times$ maximum (serum creatinine/k or 1$)^{-1.209} \times 0.993$ age $\times 1.018$ (if female), where $\mathrm{k}$ is 0.7 for females and 0.9 for males, and $\alpha$ is -0.329 for females and -0.411 for males [12]. Furthermore, the eGFR level of $60 \mathrm{~mL} / \mathrm{min} / 1.73 \mathrm{~m}^{2}$ was used as the critical measure for assessing renal function $[12,13]$. Therefore, we defined decreased renal function as the eGFR level of $<60 \mathrm{~mL} / \mathrm{min} / 1.73$ $\mathrm{m}^{2}$ on postoperative day 4 [12]. The donors were categorized into a group with postoperative eGFR $\geq$ $60 \mathrm{~mL} / \mathrm{min} / 1.73 \mathrm{~m}^{2}$ or a group with postoperative $\mathrm{eGFR}<60 \mathrm{~mL} / \mathrm{min} / 1.73 \mathrm{~m}^{2}$.

\section{Measurements}

The potential preoperative risk factors included age, sex, body mass index (BMI), diabetes mellitus, hypertension, preoperative laboratory data, and renal vascular anatomic factors. Preoperative data were obtained for glucose, albumin, sodium, potassium, uric acid, total cholesterol, creatinine, eGFR, and urine protein. Renal vascular anatomy was evaluated with computed tomography angiography, and included the number of renal arteries and veins, early renal artery bifurcation (within $2 \mathrm{~cm}$ of the aorta for left-side donors and proximal to the right wall of the inferior vena cava for right-side donors), and late confluence of the renal vein (left renal vein branch convergence within $1.5 \mathrm{~cm}$ of the aorta and right renal vein branch convergence within $1.5 \mathrm{~cm}$ of the inferior vena cava).

Intraoperative predictors, including the anesthetic used, anesthesia time, warm ischemic time, nephrectomy side (right or left), use of vasopressors, volume of crystalloid administered, and urine output were also evaluated. Warm ischemic time was defined as the time between renal arterial division and graft perfusion with cold preservation solution [14]. If the mean arterial blood pressure was $<65 \mathrm{mmHg}$ during the donor surgical procedure, vasopressors such as ephedrine or phenylephrine were administered.

Postoperative outcomes such as hospital stay duration, intensive care unit admission rate, and eGFR level at postoperative year 1 was evaluated. The duration of hospital stay was determined starting on the day after surgery, and the intensive care unit admission rate was calculated from the number of patients admitted to the intensive care unit after surgery.

\section{Statistical analysis}

Categorical data are presented as a number (percentage), and were compared by using the chi-square test or Fisher's exact test as appropriate. Continuous data are expressed as the mean $\pm S D$, and were compared by using a $t$-test or Mann-Whitney U-test as appropriate. The preoperative and postoperative eGFR levels in the postoperative eGFR $\geq 60 \mathrm{~mL} / \mathrm{min} / 1.73 \mathrm{~m}^{2}$ and postoperative eGFR $<60$ $\mathrm{mL} / \mathrm{min} / 1.73 \mathrm{~m}^{2}$ groups were compared by using two-way repeated-measures analysis of variance. All pairwise multiple comparison procedures were examined with the Holm-Sidak method. In addition, the most relevant factors associated with decreased renal function were included in the univariate logistic regression analysis. Variables with a $P$ value of $<0.05$ from the univariate logistic regression analysis were included in a stepwise multivariate logistic regression analysis to evaluate the risk factors associated with decreased renal function. A $P$ value of $<0.05$ was considered statistically significant. All statistical analyses were performed with SPSS for Windows (version 21.0; IBM-SPSS Inc., Armonk, NY) and SigmaPlot (version 12.0; Systat Software, San Jose, CA).

\section{Results}

Of 685 living renal donors who underwent hand-assisted laparoscopic donor nephrectomy by a single surgeon during the study period, 643 were included in the study (Fig. 1). A total of 337 patients $(52.4 \%)$ underwent hand-assisted laparoscopic donor nephrectomy during period 1 (2006-2009), with another 306 (47.6\%) during period 2 (2010-2013) (Table 1). There were no intraoperative conversion cases to open nephrectomy. 


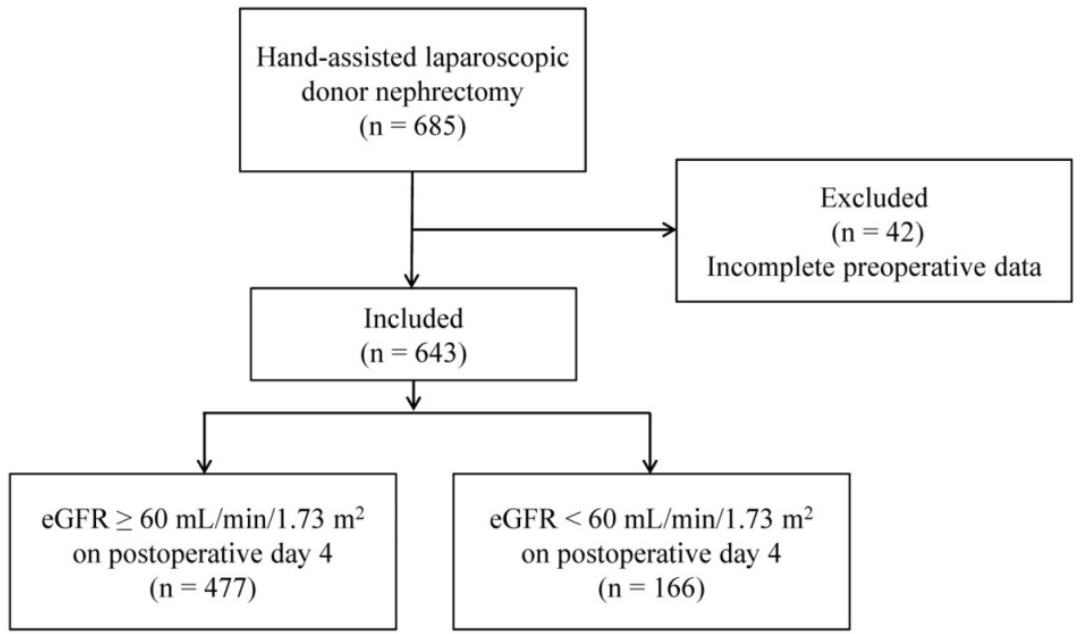

Figure 1. Flow diagram of the study participants. eGFR = estimated glomerular filtration rate.

Table 1. Clinical characteristics.

\begin{tabular}{|c|c|c|c|c|}
\hline Variables & $\begin{array}{l}\text { All } \\
(\mathrm{n}=643)\end{array}$ & $\begin{array}{l}\mathrm{eGFR} \geq 60 \mathrm{~mL} / \mathrm{min} / 1.73 \mathrm{~m}^{2} \text { on } \\
\text { postoperative day } 4(\mathrm{n}=477)\end{array}$ & $\begin{array}{l}\mathrm{eGFR}<60 \mathrm{~mL} / \mathrm{min} / 1.73 \mathrm{~m}^{2} \text { on } \\
\text { postoperative day } 4(\mathrm{n}=166)\end{array}$ & $P$ value* \\
\hline Study period & & & & 0.279 \\
\hline Period 1 (2006-2009) & $337(52.4 \%)$ & $256(53.7 \%)$ & $81(48.8 \%)$ & \\
\hline Period 2 (2010-2013) & $306(47.6 \%)$ & $221(46.3 \%)$ & $85(51.2 \%)$ & \\
\hline Age (years) & $41.5 \pm 11.0$ & $39.1 \pm 10.5$ & $48.4 \pm 9.4$ & $<0.001$ \\
\hline Sex & & & & $<0.001$ \\
\hline Female & $317(49.3 \%)$ & $263(55.1 \%)$ & $54(32.5 \%)$ & \\
\hline Male & $326(50.7 \%)$ & $214(44.9 \%)$ & $112(67.5 \%)$ & \\
\hline BMI $\left(\mathrm{kg} / \mathrm{m}^{2}\right)$ & $24.3 \pm 3.1$ & $24.1 \pm 3.1$ & $24.9 \pm 3.0$ & 0.003 \\
\hline Diabetes mellitus & $2(0.3 \%)$ & $2(0.4 \%)$ & $0(0 \%)$ & 1.000 \\
\hline Hypertension & $22(3.4 \%)$ & $15(3.1 \%)$ & $7(4.2 \%)$ & 0.874 \\
\hline \multicolumn{5}{|l|}{ Preoperative laboratory data } \\
\hline Glucose (mg/dL) & $104.3 \pm 23.9$ & $104.0 \pm 24.5$ & $105.3 \pm 22.2$ & 0.544 \\
\hline Albumin (g/dL) & $4.16 \pm 0.33$ & $4.16 \pm 0.33$ & $4.14 \pm 0.34$ & 0.475 \\
\hline Sodium (mmol/L) & $140.1 \pm 2.0$ & $139.9 \pm 2.0$ & $140.4 \pm 2.0$ & 0.007 \\
\hline Potassium (mmol/L) & $4.12 \pm 0.31$ & $4.11 \pm 0.31$ & $4.13 \pm 0.31$ & 0.410 \\
\hline Uric acid (mg/dL) & $4.9 \pm 1.3$ & $4.8 \pm 1.2$ & $5.3 \pm 1.3$ & $<0.001$ \\
\hline Total cholesterol (mg/dL) & $183.4 \pm 35.7$ & $180.6 \pm 35.4$ & $191.5 \pm 35.6$ & 0.001 \\
\hline Creatinine $(\mathrm{mg} / \mathrm{dL})$ & $0.78 \pm 0.16$ & $0.75 \pm 0.15$ & $0.89 \pm 0.15$ & $<0.001$ \\
\hline eGFR $\left(\mathrm{mL} / \mathrm{min} / 1.73 \mathrm{~m}^{2}\right)$ & $105.2 \pm 13.4$ & $109.3 \pm 11.6$ & $93.4 \pm 11.1$ & $<0.001$ \\
\hline Urine protein $(\mathrm{mg} / \mathrm{dL})$ & $5.8 \pm 2.5$ & $5.9 \pm 2.6$ & $5.7 \pm 2.0$ & 0.436 \\
\hline Number of renal arteries & & & & 0.951 \\
\hline 1 & $548(85.2 \%)$ & $407(85.3 \%)$ & $141(84.9 \%)$ & \\
\hline 2 & $86(13.4 \%)$ & $63(13.2 \%)$ & $23(13.9 \%)$ & \\
\hline 3 & $9(1.4 \%)$ & $7(1.5 \%)$ & $2(1.2 \%)$ & \\
\hline Early renal artery bifurcation & $74(11.5 \%)$ & $48(10.1 \%)$ & $26(15.7 \%)$ & 0.052 \\
\hline Number of renal veins & & & & 0.965 \\
\hline 1 & $558(86.8 \%)$ & $414(86.8 \%)$ & $144(86.8 \%)$ & \\
\hline 2 & $76(11.8 \%)$ & $56(11.7 \%)$ & $20(12.0 \%)$ & \\
\hline 3 & $9(1.4 \%)$ & $7(1.5 \%)$ & $2(1.2 \%)$ & \\
\hline Late confluence of renal vein & $35(5.4 \%)$ & $25(5.2 \%)$ & $10(6.0 \%)$ & 0.702 \\
\hline Anesthetics & & & & 0.203 \\
\hline Sevoflurane & $21(3.3 \%)$ & $17(3.6 \%)$ & $4(2.4 \%)$ & \\
\hline Desflurane & $319(49.6 \%)$ & $227(47.6 \%)$ & $92(55.4 \%)$ & \\
\hline Isoflurane & $303(47.1 \%)$ & $233(48.8 \%)$ & $70(42.2 \%)$ & \\
\hline Anesthesia time (min) & $227.9 \pm 41.8$ & $228.0 \pm 41.3$ & $227.6 \pm 43.2$ & 0.902 \\
\hline Warm ischemic time (s) & $193.9 \pm 40.9$ & $193.6 \pm 41.1$ & $194.4 \pm 40.6$ & 0.830 \\
\hline Nephrectomy side & & & & 0.076 \\
\hline Right & $289(44.9 \%)$ & $226(47.4 \%)$ & $63(38.0 \%)$ & \\
\hline Left & $354(55.1 \%)$ & $251(52.6 \%)$ & $103(62.0 \%)$ & \\
\hline Use of vasopressors & $60(9.3 \%)$ & $38(8.0 \%)$ & $22(13.3 \%)$ & 0.044 \\
\hline Crystalloid administered (mL) & $2411.0 \pm 777.4$ & $2414.1 \pm 761.7$ & $2402.0 \pm 823.1$ & 0.863 \\
\hline Urine output (mL) & $795.2 \pm 470.0$ & $786.6 \pm 477.1$ & $819.8 \pm 449.4$ & 0.433 \\
\hline
\end{tabular}


Table 2. Univariate and multivariate regression analyses of predictors associated with decreased renal function after hand-assisted laparoscopic donor nephrectomy performed by a single surgeon

\begin{tabular}{|c|c|c|c|c|}
\hline \multirow[t]{2}{*}{ Variables } & \multicolumn{2}{|l|}{ Univariate analysis } & \multicolumn{2}{|l|}{ Multivariate analysis } \\
\hline & OR $(95 \% \mathrm{CI})$ & $P$ value & OR $(95 \%$ CI) & $P$ value \\
\hline Age & 1.095 (1.073-1.117) & $<0.001$ & $1.062(1.035-1.089)$ & $<0.001$ \\
\hline \multicolumn{5}{|l|}{ Sex } \\
\hline Female & 1.000 & & 1.000 & \\
\hline Male & $2.549(1.758-3.696)$ & $<0.001$ & $3.436(2.123-5.561)$ & $<0.001$ \\
\hline BMI & 1.091 (1.030-1.155) & 0.003 & 1.093 (1.016-1.177) & 0.018 \\
\hline Diabetes mellitus & $0.000(0.000-0.000)$ & 0.999 & & \\
\hline Hypertension & $1.356(0.543-3.386)$ & 0.514 & & \\
\hline Glucose & $1.002(0.995-1.007)$ & 0.544 & & \\
\hline Albumin & $0.823(0.483-1.403)$ & 0.475 & & \\
\hline Sodium & $1.136(1.035-1.247)$ & 0.007 & $0.981(0.870-1.105)$ & 0.748 \\
\hline Potassium & $1.271(0.719-2.248)$ & 0.409 & & \\
\hline Uric acid & $1.369(1.188-1.578)$ & $<0.001$ & $1.082(0.860-1.361)$ & 0.502 \\
\hline Total cholesterol & 1.009 (1.004-1.014) & 0.001 & 1.001 (0.995-1.007) & 0.780 \\
\hline eGFR & $0.886(0.867-0.905)$ & $<0.001$ & $0.902(0.881-0.924)$ & $<0.001$ \\
\hline Urine protein & $0.971(0.901-1.046)$ & 0.436 & & \\
\hline \multicolumn{5}{|l|}{$\begin{array}{l}\text { Number of renal } \\
\text { arteries }\end{array}$} \\
\hline 1 & 1.000 & & & \\
\hline 2 & $1.054(0.630-1.763)$ & 0.842 & & \\
\hline 3 & $0.825(0.169-4.016)$ & 0.811 & & \\
\hline $\begin{array}{l}\text { Early renal artery } \\
\text { bifurcation }\end{array}$ & $1.660(0.993-2.775)$ & 0.053 & & \\
\hline \multicolumn{5}{|l|}{$\begin{array}{l}\text { Number of renal } \\
\text { veins }\end{array}$} \\
\hline 1 & 1.000 & & & \\
\hline 2 & $1.027(0.596-1.770)$ & 0.924 & & \\
\hline 3 & $0.821(0.169-3.999)$ & 0.808 & & \\
\hline $\begin{array}{l}\text { Late confluence } \\
\text { of renal vein }\end{array}$ & $1.159(0.544-2.467)$ & 0.702 & & \\
\hline \multicolumn{5}{|l|}{ Anesthetics } \\
\hline Sevoflurane & 1.000 & & & \\
\hline Desflurane & $0.581(0.190-1.772)$ & 0.340 & & \\
\hline Isoflurane & $0.741(0.517-1.063)$ & 0.104 & & \\
\hline Anesthesia time & $1.000(0.995-1.004)$ & 0.902 & & \\
\hline $\begin{array}{l}\text { Warm ischemic } \\
\text { time }\end{array}$ & $1.000(0.996-1.005)$ & 0.829 & & \\
\hline \multicolumn{5}{|l|}{$\begin{array}{l}\text { Nephrectomy } \\
\text { side }\end{array}$} \\
\hline Right & 1.000 & & 1.000 & \\
\hline Left & $1.472(1.026-2.113)$ & 0.036 & $1.525(0.964-2.413)$ & 0.071 \\
\hline $\begin{array}{l}\text { Use of } \\
\text { vasopressors }\end{array}$ & $1.765(1.010-3.083)$ & 0.046 & 1.447 (0.714-2.933) & 0.305 \\
\hline $\begin{array}{l}\text { Crystalloid } \\
\text { administered }\end{array}$ & $\begin{array}{l}0.9999 \\
(0.9998-1.0002)\end{array}$ & 0.862 & & \\
\hline Urine output & $\begin{array}{l}1.0001 \\
(0.9998-1.0005)\end{array}$ & 0.433 & & \\
\hline
\end{tabular}

$\mathrm{OR}=$ odds ratio, $\mathrm{CI}=$ confidence interval, $\mathrm{BMI}=$ body mass index, $\mathrm{eGFR}=$ estimated glomerular filtration rate.

Of the 643 donors, $166 \quad(25.8 \%)$ exhibited postoperative eGFR values $<60 \mathrm{~mL} / \mathrm{min} / 1.73 \mathrm{~m}^{2}$ (Table 1). Figure 2 demonstrates the alterations in preoperative and postoperative eGFR levels. The eGFR levels before and after surgery in the postoperative eGFR $<60 \mathrm{~mL} / \mathrm{min} / 1.73 \mathrm{~m}^{2}$ group were significantly decreased, as compared with the levels in the postoperative eGFR $\geq 60 \mathrm{~mL} / \mathrm{min} / 1.73$ $\mathrm{m}^{2}$ group $(P<0.001)$. The clinical characteristics including preoperative and intraoperative factors are listed in Table 1. There were significant differences in age, sex, BMI, sodium, uric acid, total cholesterol, creatinine, eGFR, and use of vasopressors between the two groups. However, there were no significant differences in the renal vascular anatomy between the two groups. In addition, there were no significant differences in the intraoperative factors, which included anesthetics, anesthesia time, warm ischemic time, nephrectomy side, crystalloid administered, and urine output.

In the univariate logistic regression analysis, the following factors were significantly associated with decreased postoperative renal function: age, male sex, BMI, sodium, uric acid, total cholesterol, preoperative eGFR, nephrectomy side, and use of vasopressors (Table 2). In the multivariate logistic regression analysis, the factors associated with decreased renal function were age, male sex, BMI, and preoperative eGFR (Table 2).

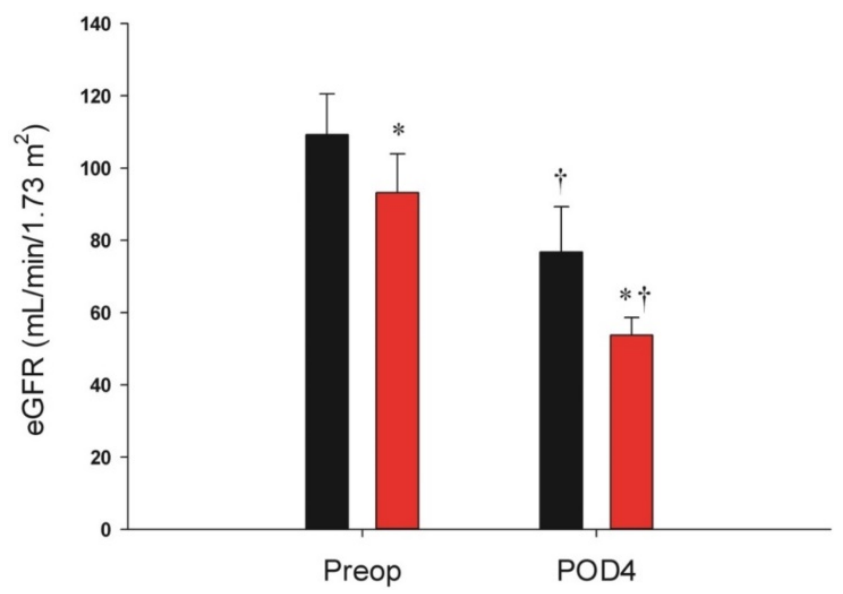

Figure 2. Changes in eGFR in the postoperative eGFR $\geq 60 \mathrm{~mL} / \mathrm{min} / 1.73 \mathrm{~m}^{2}$ group (black bar) and postoperative eGFR $<60 \mathrm{~mL} / \mathrm{min} / 1.73 \mathrm{~m}^{2}$ group (red bar) on preoperative day and postoperative day 4 . eGFR $=$ estimated glomerular filtration rate, Preop $=$ preoperative day, $\mathrm{POD} 4=$ postoperative day $4 .{ }^{*} P<$ 0.05 compared with the eGFR $\geq 60 \mathrm{~mL} / \mathrm{min} / 1.73 \mathrm{~m}^{2}$ group at each time point. $\dagger$ $P<0.05$ compared with preoperative day in each group.

There were no significant differences in the duration of postoperative hospital stay between the two groups $(5.76 \pm 1.76$ days in the postoperative eGFR $\geq 60 \mathrm{~mL} / \mathrm{min} / 1.73 \mathrm{~m}^{2}$ group and $5.60 \pm 1.74$ days in the postoperative eGFR $<60 \mathrm{~mL} / \mathrm{min} / 1.73 \mathrm{~m}^{2}$ group, $P=0.330$ ); none of the patients were admitted to the intensive care unit after hand-assisted laparoscopic donor nephrectomy. In addition, 383 of $643(59.6 \%)$ donors were analyzed at postoperative year 1 . The mean eGFR level at postoperative year 1 was $75.99 \pm 15.34 \mathrm{~mL} / \mathrm{min} / 1.73 \mathrm{~m}^{2}$. There was a significant difference in the eGFR level at postoperative year 1 between the postoperative eGFR $\geq 60 \mathrm{~mL} / \mathrm{min} / 1.73 \mathrm{~m}^{2}$ group and the postoperative 
eGFR $<60 \mathrm{~mL} / \mathrm{min} / 1.73 \mathrm{~m}^{2}$ group $(80.63 \pm 13.35$ $\mathrm{mL} / \mathrm{min} / 1.73 \mathrm{~m}^{2}$ and $63.55 \pm 13.32 \mathrm{~mL} / \mathrm{min} / 1.73 \mathrm{~m}^{2}$, respectively, $P<0.001$ ). At postoperative year 1,60 of $383(15.7 \%)$ renal donors consisting of 14 from 279 donors $(5.0 \%)$ in the postoperative eGFR $\geq 60$ $\mathrm{mL} / \mathrm{min} / 1.73 \mathrm{~m}^{2}$ group, and 46 from 104 donors $(44.2 \%)$ in the postoperative eGFR $<60 \mathrm{~mL} / \mathrm{min} / 1.73$ $\mathrm{m}^{2}$ group exhibited an eGFR level $<60 \mathrm{~mL} / \mathrm{min} / 1.73$ $\mathrm{m}^{2}(P<0.001)$.

\section{Discussion}

The major findings of the present study were that 166 of 643 donors (25.8\%) exhibited decreased postoperative renal function, defined by an eGFR level of $<60 \mathrm{~mL} / \mathrm{min} / 1.73 \mathrm{~m}^{2}$ on postoperative day 4 , and that increased age, male sex, higher BMI, and decreased preoperative eGFR were independently associated with decreased postoperative renal function. In addition, 60 donors consisting of 14 (5.0\%) from the group of 279 donors in the postoperative eGFR $\geq 60 \mathrm{~mL} / \mathrm{min} / 1.73 \mathrm{~m}^{2}$, and 46 (44.2\%) from the group of 104 donors in the postoperative eGFR $<60$ $\mathrm{mL} / \mathrm{min} / 1.73 \mathrm{~m}^{2}$ had an eGFR of $<60 \mathrm{~mL} / \mathrm{min} / 1.73$ $\mathrm{m}^{2}$ at postoperative year 1 .

Kidney transplantation is the treatment of choice for patients with end-stage renal disease; living donor renal transplantation is superior to cadaveric donor renal transplantation, with higher patient- and graft-survival rates [15]. However, donor renal function is reported to decrease by $30 \%$ to $40 \%$ after nephrectomy $[3,16]$. Therefore, it is important that alterations in renal function are evaluated after nephrectomy in order to predict decreases in renal function for the safe perioperative management of healthy donors.

Among the various types of living donor nephrectomy, hand-assisted laparoscopic donor nephrectomy is easy to learn and has a relatively flat learning curve [14]. The safety outcomes in living donors show no significant differences between hand-assisted laparoscopic donor nephrectomy and open donor nephrectomy or laparoscopic procedures [17]. However, hand-assisted laparoscopic donor nephrectomy significantly reduced the warm ischemic time and operative time compared with laparoscopic donor nephrectomy [18, 19]. In addition, the intraoperative conversion rates to open nephrectomy were higher for laparoscopic donor nephrectomy than for hand-assisted laparoscopic donor nephrectomy [7]. Therefore, hand-assisted laparoscopic donor nephrectomy has been predominantly performed at our institution. The present study included only living renal donors who underwent hand-assisted laparoscopic donor nephrectomy.
For various surgical procedures, postoperative morbidity and mortality, blood transfusions, postoperative infection, bleeding, and medical complications largely depend on the experience of a surgeon $[8,9,11,20]$. Hu et al. showed that higher operative volumes are associated with shorter lengths of stay and lower in-hospital cardiac, respiratory, vascular, wound, genitourinary, and miscellaneous medical and surgical complication rates after radical prostatectomy [8]. In addition, high-volume surgeons experienced a lower postoperative complication rate for radical prostatectomy ( $26 \%$ vs. $32 \%)$ than did low-volume surgeons [21]. In the present study, to minimize the intrinsic bias resulting from surgical experience, all of the nephrectomies were performed by a highly experienced (>1000 nephrectomies) single surgeon.

In the present study, the eGFR level of 60 $\mathrm{mL} / \mathrm{min} / 1.73 \mathrm{~m}^{2}$ on postoperative day 4 was considered to be the value directly related to abnormal renal function $[3,22,23]$. In line with our present study, the eGFR level of $60 \mathrm{~mL} / \mathrm{min} / 1.73 \mathrm{~m}^{2}$ has been used as a standard value to define abnormal renal function in donor nephrectomy [3]. In addition, postoperative renal insufficiency can be observed when the eGFR level is $<60 \mathrm{~mL} / \mathrm{min} / 1.73 \mathrm{~m}^{2}$ in patients undergoing nephrectomy for renal disease as well as donor nephrectomy [24]. Furthermore, this value is also used to assess decreased renal function in the general population [22]. Therefore, the eGFR level of $60 \mathrm{~mL} / \mathrm{min} / 1.73 \mathrm{~m}^{2}$ was selected to evaluate postoperative decreased renal function.

In hand-assisted laparoscopic donor nephrectomy, a higher preoperative age was found to be significantly associated with decreased postoperative renal function. Age at donation is considered a controversial issue. As more patients develop renal failure, a larger spectrum of potential donors, including donors with old age, are being considered, and many centers currently use living kidney donors with older ages [24, 25]. However, renal function decreases in the third decade of life [26, 27] and creatinine clearance also begins to decrease by $0.8 \mathrm{~mL} / \mathrm{min} / 1.73 \mathrm{~m}^{2}$ per year from age 40 to 80 years in healthy elderly subjects [28]. Aging is related to a high prevalence of glomerulosclerosis [29, 30]. In line with our study, Chu et al. reported that older age was associated with the development of stage 3 chronic kidney disease in donor nephrectomy [31]. Therefore, meticulous follow-up on postoperative renal function should be performed in older donors who undergo hand-assisted laparoscopic nephrectomy.

Another significant factor in the present study that correlated with decreased postoperative renal function was male sex, which is a known predictor of 
decreased renal function after donor nephrectomy [32-35]. Men are reported to show a significant decline in the GFR and effective renal plasma flow between the ages of 20 and 50 years; this result is not seen in women, who are probably protected by estrogens in the premenopausal period [36]. In addition, women are known to benefit from the protective effects, against the progression of renal diseases, of their renal structure, systemic and renal hemodynamics, diet, lipid metabolism, and blood pressure, compared with men [37, 38]. Furthermore, sex hormones affect numerous cellular processes including mesangial cell proliferation and matrix accumulation by regulating the synthesis and release of cytokines, vasoactive agents, and growth factors [37].

The present findings demonstrated that preoperative BMI is a risk factor for decreased renal function after hand-assisted laparoscopic donor nephrectomy. Higher BMI is an independent risk factor for the development and progression of chronic kidney disease [39]. In addition, it was reported that higher BMI is a significant risk factor for developing proteinuria and the appearance of progressive renal failure after non-donor unilateral nephrectomy and donor nephrectomy [40, 41]. Mjøen et al. also showed that overweight donors have lower eGFR values at 1 year after donor nephrectomy [42]. Obesity may induce renal alterations such as hyperfiltration, pathological proteinuria/albuminuria, and reduced GFR [43], and excessive adiposity is an amplifier for the risk of renal disease progression in patients with chronic kidney disease [44]. Therefore, higher BMI is associated with impaired renal function recovery after donor nephrectomy. These results can provide a better understanding of the influence of BMI on the post-nephrectomy renal function in renal donors undergoing hand-assisted laparoscopic donor nephrectomy.

Preoperative eGFR was demonstrated to be one of the independent predictors of postoperative decreased renal function in the present study. In line with the present results, Rook et al. reported that pre-donation GFR based on iothalamate clearance is a significant predictor of renal function after living kidney donation [45]. Donors with lower preoperative eGFR are known to develop chronic kidney disease after a long duration of follow-up [46]. An eGFR of $>$ $90 \mathrm{~mL} / \mathrm{min} / 1.73 \mathrm{~m}^{2}$ before donation is a protective predictor against chronic kidney disease [46]. Donors with eGFR $<80 \mathrm{~mL} / \mathrm{min} / 1.73 \mathrm{~m}^{2}$ before nephrectomy may not maintain optimal function after nephrectomy [47]. Therefore, the preoperative eGFR should be evaluated to optimize the safety of living renal donors. In addition, the eGFR was calculated by using the CKD-EPI equation in the present study, as it is less biased than the Modification of Diet in Renal Disease Study equation for most subgroups defined by demographic and clinical characteristics, and is able to more accurately evaluate renal function in patients with eGFR $\geq 60 \mathrm{~mL} / \mathrm{min} / 1.73 \mathrm{~m}^{2}$ [13].

In line with previous studies [48, 49], we found that $15.7 \%$ (60 of 383 donors) of all renal donors showed a decrease in eGFR level to $<60$ $\mathrm{mL} / \mathrm{min} / 1.73 \mathrm{~m}^{2}$ at 1 year after donor nephrectomy. More important, we also noted that $44.2 \%$ of the group whose eGFR level was measured to be $<60$ $\mathrm{mL} / \mathrm{min} / 1.73 \mathrm{~m}^{2}$ on postoperative day 4 had maintained the level at 1 year after donor nephrectomy. These results suggest that a closer observation may be required for renal donors with decreased eGFR level on postoperative day 4 in order to effectively prevent the deterioration of renal function.

A possible limitation of the present study is its retrospective design and use of medical records. The possibility of systematic errors and observer bias cannot be excluded in this retrospective analysis, although efforts were made to minimize them by accounting for all risk factors potentially affecting decreased renal function during the perioperative period.

In conclusion, the present study demonstrated that increased age, male sex, higher BMI, and decreased preoperative eGFR are associated with decreased renal function after hand-assisted laparoscopic donor nephrectomy performed by a single experienced surgeon. Notably, the potential bias resulting from the surgeon and operative technique was minimized by using the outcomes of a single technique performed by a single surgeon. These results provide important information for optimal perioperative management to maximize safety for living renal donors.

\section{Abbreviations}

BMI: body mass index, CKD-EPI: Chronic Kidney Disease Epidemiology Collaboration, eGFR: estimated glomerular filtration rate.

\section{Conflict of interests}

The authors stated that there are no conflicts of interest regarding the publication of this article.

\section{References}

1. Ahmadi AR, Lafranca JA, Claessens LA, Imamdi RMS, Ijzermans JNM, Betjes $\mathrm{MGH}$, et al. Shifting paradigms in eligibility criteria for live kidney donation: a systematic review. Kidney International. 2015; 87: 31-45.

2. Ommen ES, Winston JA, Murphy B. Medical risks in living kidney donors: absence of proof is not proof of absence. Clin J Am Soc Nephrol. 2006; 1 : 885-95.

3. Lee JH, Kim SC, Han DJ, Chang JW, Yang WS, Park SK, et al. Risk factors for MDRD-GFR of less than $60 \mathrm{~mL} / \mathrm{min}$ per $1.73 \mathrm{~m}^{2}$ in former kidney donors. Nephrology. 2007; 12: 600-6. 
4. Jeon HG, Lee SR, Joo DJ, Oh YT, Kim MS, Kim YS, et al. Predictors of kidney volume change and delayed kidney function recovery after donor nephrectomy. J Urol. 2010; 184: 1057-63.

5. Provoost AP, Baudoin P, De Keijzer MH, Van Aken M, Molenaar JC. The role of nephron loss in the progression of renal failure: experimental evidence. Am J Kidney Dis. 1991; 17: 27-32.

6. Stifelman MD, Hull D, Sosa RE, Su LM, Hyman M, Stubenbord W, et al. Hand assisted laparoscopic donor nephrectomy: a comparison with the open approach. J Urol. 2001; 166: 444-8.

7. Kocak B, Baker TB, Koffron AJ, Leventhal JR. Laparoscopic living donor nephrectomy: a single-center sequential experience comparing hand-assisted versus standard technique. Urology. 2007; 70: 1060-3.

8. Hu JC, Gold KF, Pashos CL, Mehta SS, Litwin MS. Role of surgeon volume in radical prostatectomy outcomes. J Clin Oncol. 2003; 21: 401-5.

9. Dash A, Dunn RL, Resh J, Wei JT, Montie JE, Sanda MG. Patient, surgeon, and treatment characteristics associated with homologous blood transfusion requirement during radical retropubic prostatectomy: multivariate nomogram to assist patient counseling. Urology. 2004; 64: 117-22

10. Cowan JA, Jr., Dimick JB, Thompson BG, Stanley JC, Upchurch GR, Jr. Surgeon volume as an indicator of outcomes after carotid endarterectomy: an effect independent of specialty practice and hospital volume. J Am Coll Surg. 2002; 195: 814-21.

11. Stavrakis AI, Ituarte PH, Ko CY, Yeh MW. Surgeon volume as a predictor of outcomes in inpatient and outpatient endocrine surgery. Surgery. 2007; 142: 887-99; discussion -99.

12. Matsushita K, Mahmoodi BK, Woodward M, Emberson JR, Jafar TH, Jee SH, et al. Comparison of risk prediction using the CKD-EPI equation and the MDRD study equation for estimated glomerular filtration rate. Jama. 2012; 307: 1941-51

13. Stevens LA, Schmid CH, Greene T, Zhang Y, Beck GJ, Froissart M, et al. Comparative Performance of the CKD Epidemiology Collaboration (CKD-EPI) and the Modification of Diet in Renal Disease (MDRD) Study Equations for Estimating GFR Levels Above $60 \mathrm{~mL} / \mathrm{min} / 1.73 \mathrm{~m} 2$. American Journal of Kidney Diseases. 2010; 56: 486-95.

14. Song G, Jeong IG, Kim YH, Han DJ, Kim CS, Ahn H, et al. Kidney Laterality and the Safety of Hand-assisted Live Donor Nephrectomy: Review of 1000 Consecutive Cases at a Single Center. Urology. 2015; 85: 1360-6.

15. Jüngst D, Wallner J, Karl HJ. Correlation of total cholesterol and protein in urine in patients with the NEPHROTIC syndrome. Klinische Wochenschrift. 1980;58: 1215-6.

16. Ibrahim HN, Foley R, Tan L, Rogers T, Bailey RF, Guo H, et al. Long-Term Consequences of Kidney Donation. New England Journal of Medicine. 2009; 360: 459-69.

17. Qunibi WY. Dyslipidemia and progression of cardiovascular calcification (CVC) in patients with end-stage renal disease (ESRD). Kidney Int Suppl. 2005;: S43-50.

18. Yoon YE, Choi KH, Lee KS, Kim KH, Yang SC, Han WK. Impact of metabolic syndrome on postdonation renal function in living kidney donors. Transplant Proc. 2015; 47: 290-4.

19. Joles JA, Kunter U, Janssen U, Kriz W, Rabelink TJ, Koomans HA, et al. Early mechanisms of renal injury in hypercholesterolemic or hypertriglyceridemic rats. J Am Soc Nephrol. 2000; 11: 669-83.

20. Lee YS, Jeon HG, Lee SR, Jeong WJ, Yang SC, Han WK. The feasibility of solo-surgeon living donor nephrectomy: initial experience using video-assisted minilaparotomy surgery. Surgical Endoscopy. 2010; 24: 2755-9.

21. Segev DL, Muzaale AD, Caffo BS, Mehta SH, Singer AL, Taranto SE, et al. Perioperative mortality and long-term survival following live kidney donation. Jama. 2010; 303: 959-66.

22. Stevens LA, Coresh J, Greene T, Levey AS. Assessing Kidney Function Measured and Estimated Glomerular Filtration Rate. New England Journal of Medicine. 2006; 354: 2473-83.

23. Lane BR, Demiriian S, Weight CJ, Larson BT, Poggio ED, Campbell SC Performance of the Chronic Kidney Disease-Epidemiology Study Equations for Estimating Glomerular Filtration Rate Before and After Nephrectomy. The Journal of Urology. 2010; 183: 896-902.

24. Rook M, Hofker HS, Van Son WJ, Homan van der Heide JJ, Ploeg RJ, Navis GJ. Predictive Capacity of Pre-Donation GFR and Renal Reserve Capacity for Donor Renal Function After Living Kidney Donation. American Journal of Transplantation. 2006; 6: 1653-9.

25. Kim HO, Chae SY, Baek S, Moon DH. Factors affecting changes in the glomerular filtration rate after unilateral nephrectomy in living kidney donors and patients with renal disease. Nucl Med Mol Imaging. 2010; 44: 69-74.

26. Epstein M. Aging and the kidney. J Am Soc Nephrol. 1996; 7: 1106-22.

27. Rowe JW, Andres R, Tobin JD, Norris AH, Shock NW. The effect of age on creatinine clearance in men: a cross-sectional and longitudinal study. J Gerontol. 1976; 31: 155-63.

28. Rowe JW, Shock NW, DeFronzo RA. The influence of age on the renal response to water deprivation in man. Nephron. 1976; 17: 270-8

29. Kasiske BL. Relationship between vascular disease and age-associated changes in the human kidney. Kidney Int. 1987; 31: 1153-9.

30. Kappel B, Olsen S. Cortical interstitial tissue and sclerosed glomeruli in the normal human kidney, related to age and sex. A quantitative study. Virchows Arch A Pathol Anat Histol. 1980; 387: 271-7.
31. Chu $\mathrm{KH}$, Poon $\mathrm{CK}$, Lam CM, Cheuk A, Yim KF, Lee W, et al. Long-term outcomes of living kidney donors: a single centre experience of 29 years. Nephrology (Carlton). 2012; 17: 85-8.

32. Anderson RG, Bueschen AJ, Lloyd LK, Dubovsky EV, Burns JR. Short-term and long-term changes in renal function after donor nephrectomy. J Urol. 1991; 145: 11-3.

33. Bello RC, Bello VA, Rosa TT, Junqueira Jr LF, Freitas E, Veiga JPR. Male Gender and Body Mass Index Are Associated With Hypertension and Reduced Kidney Function 5 or More Years After Living Kidney Donation. Transplantation Proceedings. 2015; 47: 2816-21.

34. Gibney EM, Parikh CR, Garg AX. Age, gender, race, and associations with kidney failure following living kidney donation. Transplant Proc. 2008; 40: 1337-40.

35. Ohashi Y, Thomas G, Nurko S, Stephany B, Fatica R, Chiesa A, et al. Association of metabolic syndrome with kidney function and histology in living kidney donors. Am J Transplant. 2013; 13: 2342-51.

36. Berg UB. Differences in decline in GFR with age between males and females. Reference data on clearances of inulin and PAH in potential kidney donors. Nephrol Dial Transplant. 2006; 21: 2577-82.

37. Neugarten J, Golestaneh L. Gender and the prevalence and progression of renal disease. Adv Chronic Kidney Dis. 2013. 20: 390-5.

38. Silbiger SR, Neugarten J. The impact of gender on the progression of chronic renal disease. Am J Kidney Dis. 1995; 25: 515-33.

39. Bolignano D, Zoccali C. Effects of weight loss on renal function in obese CKD patients: a systematic review. Nephrol Dial Transplant. 2013; 28 Suppl 4: iv82-98

40. Praga M, Hernandez E, Herrero JC, Morales E, Revilla Y, Diaz-Gonzalez R, et al. Influence of obesity on the appearance of proteinuria and renal insufficiency after unilateral nephrectomy. Kidney Int. 2000; 58: 2111-8.

41. Bello RC, Bello VA, Rosa TT, Junqueira LF, Jr., Freitas E, Veiga JP. Male Gender and Body Mass Index Are Associated With Hypertension and Reduced Kidney Function 5 or More Years After Living Kidney Donation. Transplant Proc. 2015; 47: 2816-21.

42. Mjøen G, Oyen O, Midtvedt K, Dahle DO, Norby G, Holdaas H. Age, gender, and body mass index are associated with renal function after kidney donation. Clin Transplant. 2011; 25: E579-83.

43. Ix JH, Sharma K. Mechanisms linking obesity, chronic kidney disease, and fatty liver disease: the roles of fetuin-A, adiponectin, and AMPK. J Am Soc Nephrol. 2010; 21: 406-12.

44. Othman M, Kawar B, El Nahas AM. Influence of obesity on progression of non-diabetic chronic kidney disease: a retrospective cohort study. Nephron Clin Pract. 2009; 113: c16-23.

45. Begg CB, Riedel ER, Bach PB, Kattan MW, Schrag D, Warren JL, et al. Variations in morbidity after radical prostatectomy. N Engl J Med. 2002; 346: 1138-44.

46. Tsai SF, Shu KH, Wu MJ, Ho HC, Wen MC, Su CK, et al. A higher glomerular filtration rate predicts low risk of developing chronic kidney disease in living kidney donors. World J Surg. 2013; 37: 923-9.

47. Norden G, Lennerling A, Nyberg G. Low absolute glomerular filtration rate in the living kidney donor: a risk factor for graft loss. Transplantation. 2000; 70: 1360-2.

48. Tent H, Sanders J-SF, Rook M, Hofker HS, Ploeg RJ, Navis G, et al. Effects of Preexistent Hypertension on Blood Pressure and Residual Renal Function After Donor Nephrectomy. Transplantation. 2012; 93: 412-7.

49. Song $\mathrm{T}, \mathrm{Fu} \mathrm{L}$, Huang $\mathrm{Z}, \mathrm{He} \mathrm{S}$, Zhao $\mathrm{R}$, Lin $\mathrm{T}$, et al. Change in renal parenchymal volume in living kidney transplant donors. International Urology and Nephrology. 2014; 46: 743-7. 